\title{
David Oliver: What might Health Education England's workforce strategy mean for doctors?
}

\author{
David Oliver consultant in geriatrics and acute general medicine
}

Berkshire

It may seem extraordinary but, in the NHS's entire history, we've never seen anything resembling a comprehensive, medium term workforce strategy. The NHS has tended to rely rather complacently on staff from overseas, while failing to consider the growing number of less than full time workers or the effects of new roles in the clinical workforce.

Last week we learnt from NHS Improvement that around 100 000 NHS posts (one in 11) are unfilled, including $8 \%$ of medical posts. ${ }^{1}$ I therefore commend Health Education England's timeliness in publishing a draft workforce strategy, Facing the Facts, Shaping the Future, in December 2017. ${ }^{2}$ For this to have happened may have taken a huge workforce crisis-and a storm of protest from health professionals and in the media-but (some) credit where it's due.

The document, which is now out for public consultation, ${ }^{3}$ contains a detailed description of current workforce numbers and challenges. For transparent figures about current staffing to help counter government spin, it's a goldmine.

So, what does the workforce plan say about doctors? It contains a fair bit on career flexibility, morale, logistical support, cutting bureaucracy, working less than full time, millennial doctors' expectations, and how we might support older doctors to keep working in the NHS. All good stuff, but the strategy will be judged on whether employers or national bodies implement any of these aspirations in a way that we notice.

It proposes reducing workload and liberating doctors to work at the top of their training and big expansions of physician associate and nursing associate roles. It also mentions the planned additional 1500 new medical student places ${ }^{4}$ and the need for some of these to be in regions relatively short of doctors.

But it says little about attrition from the profession at training, GP, or consultant stage or the growing numbers going less than full time, meaning that 1500 new medical school places will not translate to 1500 whole time equivalent doctors or make the NHS self sufficient. It reiterates government plans to recruit 5000 more GPs by 2020, but it doesn't mention that this initiative is currently way off target and that we actually have 1000 fewer GPs this year than last.'

The strategy will be judged on whether employers or national bodies implement any of these aspirations in a way that we notice

Nowhere does the strategy propose increases in training numbers in secondary care medical specialties. I suspect that the Treasury might have vetoed any plans for expansion, given the cost. It's likely that Health Education England considered the Home Office and its stance on immigration, given that around one in five NHS doctors is an overseas graduate (and around half of those from non-EU countries), yet with visas strictly limited. ${ }^{67}$

It says nothing of practical use in tackling the very current issues of major rota gaps in acute specialties; the high percentage of consultant posts now unfilled at interview ${ }^{8}$; the impact on medical morale, recruitment, and retention from a fall in real terms earnings; or contract disputes.

What it especially doesn't do is set out a clear vision of just how many additional clinical staff we will need over the next 10 to 20 years to make the NHS model sustainable against a background of demographic change.

It will be interesting to see the consultation responses, especially from fellow doctors. But a consultation on these issues is at least a start in tackling some of these problems.

Competing interests: See www.bmj.com/about-bmj/freelance-contributors/davidoliver.

Provenance and peer review: Commissioned; not externally peer reviewed.

Follow David on Twitter: @mancunianmedic

Siddique H. NHS England has one in 11 posts unfilled. Guardian 21 Feb 2018. https:// www.theguardian.com/society/2018/feb/21/nhs-england-has-one-in-11-posts-unfilled. Health Education England. Facing the facts, shaping the future: a draft health and care workforce strategy for England to 2027. Dec 2017. https://www.hee.nhs.uk/sites/default/ files/documents/Facing\%20the\%20Facts\%252c\%20Shaping\%20the\%20Future\%20\% $281 \% 29$.pdf.

3 Health Education England. Consultation on workforce strategy (open until 23 March 2018). Dec 2017. https://consultation.hee.nhs.uk/welcome-page. 
4 Department of Health and Social Care. 1500 extra medical undergraduate places confirmed. 9 Aug 2017. https://www.gov.uk/government/news/1500-extra-medicalundergraduate-places-confirmed.

5 Kaffash J. Will the NHS deliver 5000 extra GPs by 2020?Pulse 2017:31.www.pulsetoday co.uk/hot-topics/general-practice-forward-view/will-the-nhs-deliver-5000-extra-gps-by2020/20034160.article

6 Matthews-King A. Reliance on overseas doctors makes NHS vulnerable to crisis after Brexit, warns watchdog. Independent 19 Dec 2017. www.independent.co.uk/news/health/ nhs-brexit-overseas-doctors-staffing-hospitals-nurses-leave-eu-withdrawal-healthcarea8118441.html.
7 Gallagher P. NHS doctors blocked from coming to work in the UK. iNews 16 Jan 2018. https://inews.co.uk/news/health/nhs-doctors-blocked-coming-work-uk/.

8 Royal College of Physicians. Underfunded, underdoctored, overstretched: the NHS in 2016. 21 Sept 2016. https://www.rcplondon.ac.uk/guidelines-policy/underfundedunderdoctored-overstretched-nhs-2016.

Published by the BMJ Publishing Group Limited. For permission to use (where not already granted under a licence) please go to http://group.bmj.com/group/rights-licensing/ permissions 